DOI 10.37882/2500-3682.2021.12.08

\title{
ВОЗМОЖНОСТИ КОМПЛЕКСНОГО ПАТОПСИХОЛОГИЧЕСКОГО ИССЛЕДОВАНИЯ РАССТРОЙСТВ ОРГАНИЧЕСКОГО СПЕКТРА
}

\section{THE POSSIBILITIES OF A COMPREHENSIVE PATHOPSYCHOLOGICAL STUDY OF ORGANIC SPECTRUM DISORDERS \\ Ya. Zhakupova \\ M. Ovchinnikov \\ Ya. Mokina}

Summary: The article presents the results of the pathopsychological diagnosis of mental disorders in patients suffering from organic spectrum disorders. Demonstrated the possibilities of a comprehensive pathopsychological study necessary for a clinical psychologist to further develop psychological rehabilitation programs and improve the quality of life of patients with psycho-organic syndrome.

Keywords: methods of pathopsychological research, organic spectrum disorders, endogenous-organic pathopsychological syndrome, exogenous-organic pathopsychological syndrome.
Жакупова Яна Тураровна

К.nсх.н., дочент, ФГБОУ ВО «Южно-Уральский государственный медицинский университет» Министерства здравоохранения Российской Федерации,

2. Челябинск

ps-gold@yandex.ru

Овчинников Михаил Владимирович

К.nсх.н., дочент, ФГБОУ ВО «Челябинский государственный университет», г. Челябинск ovmv@mail.ru

Мокина Яна Валерьевна

Заведующая отделением, врач-психиатр, Челябинская областная клиническая специализированная психоневрологическая больница №1, г. Челябинск vale1205@yandex.ru

Аннотация: В статье представлены результаты патопсихологической диагностики психических нарушений у больных, страдающих расстройствами органического спектра. Продемонстрированные возможности комплексного патопсихологического исследования, необходимого клиническому психологу для дальнейшей разработки программ психологической реабилитации и повышения качества жизни пациентов с психоорганическим синдромом.

Ключевые слова: методы патопсихологического исследования, расстройства органического спектра, эндогенно-органический патопсихологический синдром, экзогенно-органический патопсихологический синдром.

\section{Введение}

K омплексное патопсихологическое исследование, направленное на решение диагностических или экспертных задач, предоставляет возможность медицинскому психологу провести оценку психики пациента как целостной системы. Выявление «точек» распада психики и ее сохранных сторон определяет дальнейший характер построения и проведения психологом программы реабилитации. По мнению Б.В. Зейгарник, именно такой подход отражает специфику патопсихологического эксперимента, поскольку определение любого психического расстройства требует от диагноста тщательного изучения условий, причин его развития и выявления механизмов симптомообразования [1].

При осуществлении диагностической работы, проводимой в рамках экспериментально-патопсихологических исследований необходимо помнить о специфике выбора и применения методов исследования. Назовем некоторые из них.

1. Отличие патопсихологического исследования от процедур общепсихологической диагностики заключается в тщательном анализе диагностом всех компонентов поведения испытуемого: реакции на инструкцию к выполнению и содержание предлагаемых заданий; трудности, возникающие в процессе их выполнения; динамику протекания психической деятельности и пр. Очень важен для исследования показатель заинтересованности пациента в своих результатах. С.Я. Рубинштейн утверждала, что, «...чем сохраннее личность, тем обычно глубже выражена эмоциональная реакция на исследование в целом ... безучастное отношение к факту исследования наблюдается при глубоком распаде личности либо при очень глубокой депрессии» [2, с.174].

2. Правомерность утверждения о снижении когнитивных функций может присутствовать в патопсихологическом заключении лишь тогда, когда их сформированность соответствовала возрасту, полученному образованию и социальному статусу пациента еще до первых клинических проявлений заболевания, что обязательно должно быть указано в анамнезе больных.

3. При использовании методов диагностики аффективной сферы, а также личностных особенностей пациентов с расстройствами органического 
спектра, следует учитывать наличие сочетанной патологии (например, заболевания головного мозга экзогенно-органического происхождения и депрессивные невротические расстройства), а также некоторых форм психических заболеваний.

4. Вариативность проявлений патопсихологической картины при расстройствах органического спектра позволяет увидеть психологу дифференциальная диагностика, в процессе которой отграничиваются органические расстройства от патологий иного характера (форм умственной отсталости, эпилепсии, возрастной незрелости и пр.) (автореф. Королев Возможности). Выявление своеобразных дискриминативных маркеров способствует преодолению дифференциально-диагностических трудностей и возможности более точного распознавания сочетанной и органической патологии в связи с часто схожими патопсихологическими нарушениями, проявляющимися при указанных расстройствах.

5. У пациентов, страдающих психическими заболеваниями, могут наблюдаться повышенная утомляемость и истощаемость психических процессов, низкий уровень умственной работоспособности, что напрямую отражается в продолжительность проведения патопсихологического исследования.

6. В отличие от психологического эксперимента, где диагност не имеет право влиять на ход исследования, патопсихологический эксперимент представляет собой взаимную деятельность экспериментатора и испытуемого. Как отмечает Б.В. Зейгарник «как бы жестка ни была инструкция, часто взгляд экспериментатора, его мимика могут изменить ситуацию эксперимента, отношение больного», что приведет к изменению его действий, установок и мотивации [1, с. 42].

7. В результате комплексного патопсихологического исследования определяется патопсихологический синдром как «патогенетически обусловленная общность внутренне взаимообусловленных и взаимосвязанных признаков психических расстройств» [3, с. 34]. что позволяет выявить системную природу патологии психической деятельности.

Многообразие встречающихся нарушений при расстройствах органического спектра в современной клинической психологии отражены в понятии «психоорганический синдром» (далее - ПОС). Именно использование этого термина позволяет по совокупности расстройств оценить степень и глубину органических изменений личности, их характер и выраженность. Клинико-патопсихологические характеристики данного синдрома сформировались в представления о ПОС, как жесткой структуре следующих признаков - состоянии общей психической беспомощности с нарушениями па- мяти, интеллекта, выраженном эмоциональном недержании (так называемая триада H. Walter-Buel).

По классификации С.Л. Соловьевой, психоорганический синдром выступает в двух вариантах: экзогенно-органическом и эндогенно-органическом [4,с. 80].

Заболевания головного мозга травматического генеза входят в группу нозологий, составляющих основу патопсихологического экзогенно-органического синдрома, где степень психических нарушений (особенно когнитивных) зависит от степени травматизации больного. Так, состояние легкого когнитивного расстройства характеризуется начальными признаками снижения когнитивной продуктивности (сужением объема внимания, снижением его концентрации и устойчивости; возникновением постоянной забывчивости, нарушением продуктивности оперативной памяти, селективности, целенаправленности и категориальности мышления), а также появлением психической истощаемости. При более глубоком уровне нарушений названные расстройства приобретают характер грубых расстройств интеллектуальной деятельности, что приводит к значительному ухудшению в социальной и профессиональной деятельности и частичной либо полной потере сохранности повседневных видов активности.

В клинике эндогенно-органического синдрома присутствуют эпилепсия и психические расстройства при первичных дегенеративных (атрофических) процессах головного мозга.

Для психических расстройств, встречающихся при первичных атрофических процессах характерно медленное, прогредиентное течение, переходящее в хроническую форму. В начале болезни выявляются слабовыраженные когнитивные и личностные изменения, постепенно нарастающие и достигающие стадии полного распада всех психических процессов, включая нарушения высших корковых и подкорковых функций.

Психические нарушения при эпилепсии, в большинстве своем, связаны с изменениями личности (напряженность и вязкость аффектов), находящими отражение в торпидности психических процессов (восприятии, внимании, памяти) и приводящие некоторых больных к специфическому (концентрическому) слабоумию [5, c. 165].

Цель исследования - определение клинико-психологических особенностей пациентов, страдающих ПОС в связи с задачами дифференциальной диагностики.

\section{Материалы и методы}

Возможности применения комплексного патопси- 
хологического исследования при расстройствах органического спектра различного генеза представлены в контексте следующих индивидуальных клинических случаев. В исследовании использованы все группы методов патопсихологического исследования: клинико-психологический (анализ контакта с пациентом, наблюдение за поведением, клиническая беседа), клинико-биографический (изучение анамнеза) и экспериментально-психологический (патопсихологический эксперимент). Экспериментальные методики, использованные в ходе исследования: «Запоминание 10 слов» (А.Р. Лурия»); таблицы Шульте, «Толкование метафор и пословиц» (С.Я. Рубинштейн), «Исключение понятий» (С.Х. Сафонова), «Классификация предметов» (К. Гольдштейн в модификации Л.С. Выготского и Б.В. Зейгарник), Миннесотский многофакторный личностный опросник (MМРI). Кроме того, для анализа психической деятельности были использованы данные электроэнцефалографического исследования головного мозга (ЭЭГ).

В исследовании принимали участие пациенты Челябинской областной клинической специализированной психоневрологической больницы №1.

\section{Результаты и обсужкение}

Клинический случай №1. Пациент А. Возраст: 57 лет. Пол: М.

Диагноз: Органический галлюциноз. Эпилепсия.

Работал механиком на ремонтном заводе, был женат, в браке родилась дочь. Несколько лет назад получил производственную травму, после которой изменилось поведение и появились когнитивные проблемы («почувствовал что-то не то»). Развелся, в настоящий момент проживает с матерью. С коллегами и друзьями контакты утеряны.

Общается неохотно, на вопросы отвечает в плане заданного после некоторой паузы. Ответы односложные, отмечаются трудности вербализации, забывания слов. Жалоб на свое самочувствие не высказывает, считает себя здоровым, демонстрирует недовольство проводимым исследованием. Мотивация к работе с психологом снижена, к достижению положительного результата при выполнении заданий не стремится. Эмоциональный фон неустойчивый, легко раздражается, критикует содержание методик, внешние обстоятельства обследования (процедуру проведения, шум посторонних в отделении, «тусклое» освещение). При выполнении заданий испытывает затруднения в понимании и осознании инструкции, для ответа требуется достаточное количество времени (среднее латентное время ответа - 3 сек). Отмечаются трудности сосредоточения внимания на выполняемом задании, постоянная отвлекаемость на происходящее вокруг (поворачивается при появлении новых звуков, движений экспериментатора), при возвращении к выполнению заданию необходимо время для повторного включения в работу. К концу исследования сообщает об усталости.

Данные ЭЭГ: зафиксированы признаки выраженной дезорганизации биоэлектрической активности головного мозга по типу гиперсинхронизации всех ритмов. Зафиксирована эпилептиформная активность - при ГВ - комплексы «острая-медленная волна» в префронтальных областях с 2-х сторон без генерализации (локальные очаги возбуждения). Для пациента свойственна выраженная неустойчивость функционального состояния при нагрузках.

При исследовании динамики мыслительной деятельности отмечается инертность (вязкость) мышления, что в свою очередь приводит к снижению операций обобщения и отвлечения. Так, в пробе «грабеж, кража, землетрясение, поджег, нападение» (методика «Исключение понятий») испытуемый, прежде чем выбрать лишнее слово, подробно объяснял негативные последствия каждой ситуации. В конце пробы зачеркнул все слова, объяснив это тем, что «все они плохие и ему бы не хотелось оказаться в такой ситуации».

При выполнении методики «Классификация предметов» обнаружены негрубые нарушения мышления с последующим чередованием групп обобщенных и конкретно-ситуационных карточек (в начале работы пациент начал верную раскладку карточек по обобщенному принципу - одежда, мебель, животные, растения, но в процессе дальнейшего исследования стал испытывать трудности с отнесением мелких групп карточек в более укрупненные группы, например, фрукты и овощи в группу растений)

При выполнении методики «Запоминание 10 слов» у испытуемого выявляется резкое снижение объема памяти, особенно, к концу эксперимента: 5,4,2,1,1.

При выполнении методики «Таблицы Шульте» выявлены выраженные изменения темпа психической деятельности: снижение способности к концентрации и устойчивости внимания, колебания работоспособности, признаки повышенной истощаемости. При отыскивании чисел по таблицам показал следующее время: 1 мин. 30 с.; 1 мин. 50 с.; 2 мин. 58 с.

При исследовании операциональной стороны психической деятельности наблюдается тенденция к непосредственности представлений и конкретности суждений, что может свидетельствовать о низком уровне обобщения. При выполнении методики «Толкование пословиц» незнакомый материал не поясняет, ссылаясь 
на незнание. Однако при интерпретации знакомых пословиц пациент демонстрирует искаженное понимание скрытого смысла с последующим переходом в резонерство. Так, при работе с пословицей «Цыплят по осени считают», первой реакцией пациента оказалась жалоба на затруднение в понимании задания. При повторном прочтении было высказано предположение что, «после осени идет зима, а зимой цыплята вырастут в больших куриц. Не все цыплята могут пережить зиму, поэтому их будут считать только следующей осенью. Там урожай большой, цыплятам не всем хватает на корм, вот поэтому курицу потом и продают».

Эмоционально-личностная сфера. По результатам методики MMPI профиль пациента достоверный, признаков аггравации, симуляции и рентной установки не выявлено (показатели шкал L и F располагаются в нормативном диапазоне от 50 до 70 баллов). Наблюдается подъем по шкале достоверности $F$, что может быть вызвано влиянием астеничной симптоматики на выполнение большого количества заданий опросника.

Выявлен значительный подъем по шкалам «невротической триады» (Hs 75, D 76, Ну 70), что проявляется в чрезмерной фиксации пациента на собственных болезненных переживаниях, инертности в принятии решений, астеничности, недостаточности побуждающих действий. Зафиксированный пик по четвертой шкале (Pd 68) с незначительным подъёмом по шкале 9 (Ма 63) указывает на присутствие в аффективной сфере пациента агрессивных тенденций, что является характерным признаком заболеваний, имеющих экзогенно-органическую природу. Раздражительность, враждебность, недоверчивость и повышенной требовательность к окружению - все это демонстрировал испытуемый во время проведения исследования.

Несмотря на демонстрируемые в процессе исследования признаки недовольства при объявлении окончания обследования пациент поблагодарил психолога и выразил заинтересованность в его результатах.

Клинический случай №2. Пациент В. Возраст: 44 года. Пол: М.

Диагноз: Органическое шизофреноподобное расстройство. Галлюцинаторный синдром. Состояние отмены, при синдроме зависимости от алкоголя.

После демобилизации из армии устроился работать в вагон-ресторан официантом. В одном из рейсов был выброшен на полном ходу из поезда группой подвыпивших пассажиров. Был найден обходчиками, от медицинской помощи отказался. От родных (проживал с матерью и сестрой) случившееся событие скрыл («чтобы не расстраивать»). По истечении года после перенесенной травмы, со слов матери, родственники стали замечать «странное поведение сына»: обвинение родных в желании его отравить, подкладывании в пищу ядов; свою комнату, желание спрятать столовые принадлежности (ножи, вилки) в своем письменном столе; неоднократный поджог дома (семья проживала в частном секторе).

На момент исследования пациент находится в ясном состоянии сознания. Ориентирован в месте, времени и собственной личности. В беседе жалуется на снижение памяти, замедленность реакций. Эмоциональные проявления выражены слабо, голос ровный, при появлении зрительного контакта взгляд не отводит. Отмечаются стереотипные покачивания ноги, стереотипные движения рук (перебирание пальцами). Говорит не спонтанно, на вопросы экспериментатора отвечает в плане заданного, но кратко и формально. К исследованию проявляет слабый интерес, испытывает затруднения в осознании содержания заданий, среднее латентное время ответа 5 сек. Реакция на ошибки, возникающие во время исследования - адекватная.

Данные ЭЭГ: наблюдаются признаки выраженной дезорганизации биоэлектрической активности головного мозга с тотальной десинхронизацией альфа-ритма. Локальной и пароксизмальной активности не выявлено. Зафиксировано снижение уровня межполушарного взаимодействия по всем областям коры, снижение уровня внутриполушарного взаимодействия в правой лобновисочной области.

Динамика мыслительной деятельности. При выполнении методики «Таблицы Шульте» при отыскивании чисел в таблицах тратил более 1,5 минут на каждую (1 мин. 30с.; 1 мин 45с.: 1 мин. 50 с.), наблюдалась формальность мотива исследования и сильная отвлекаемость на внешние раздражители.

При выполнении методики «Запоминание 10 слов» был зафиксирован феномен «плато» (3/5/7/7/6). Нарушен мотивационный компонент памяти, испытуемый не желал запоминать слова, предлагал заняться чем-нибудь другим, утверждая, что выполнял эту методику ранее.

Операциональной стороны психической деятельно$\mathrm{cmu}$.

При выполнении методики «Толкование метафор и пословиц», отмечается непонимание переносного смысла выражений, тенденция к разноплановости суждений, актуализация конкретных и слабых латентных признаков. Ошибочные суждения не корректирует, ошибок не видит. Так, значение фразеологизма «Вбить себе в голову» испытуемый объяснил «наполненным комком в голове». При толковании выражения «Яблоко от яблони недалеко падает» пациент сначала стал вспоминать 
характеристики плодов, впоследствии переводя рассуждения на тему «первородного греха Адамы и Евы. Метафору «Душа ушла в пятки» испытуемый объяснил, как неверное суждение, потому что считает, что «душа уходит из человека через голову».

Низкий уровень обобщения и абстрагирования наблюдается при выполнении методики «Исключение лишнего». Прослеживаются мотивационные нарушения в виде разноплановости суждений, не отличающихся единым характером; наряду с категориальными признаками присутствует актуализация латентных. Пациент, просматривая стимульный материал заострял внимание на особенностях формулировок в постановке вопросов. При выполнении задания присутствовал феномен соскальзывания (в пробе «дряхлый, маленький, старый, изношенный, ветхий» не увидел ни одного лишнего слова, однако пояснил, что так «говорят про гномов»).

\section{Эмочионально-личностная сфера}

По результатам методики MMPI профиль пациента достоверный, признаков аггравации, симуляции и рентной установки не выявлено (показатели шкал L, F, K располагаются в нормативном диапазоне от 50 до 70 баллов).

Наблюдается значительный подъем по шкалам психотической тетрады (Pa 80, Sc 88, Мa 79). Данная особенность указывает на аффективную и когнитивную ригидность, склонность к подозрительности, сверхнормативность, нонконформизм, ( $6 \uparrow 8)$. При формально адекватных контактах личность демонстрирует эмоциональную холодность, сухость аффекта и поведенческий стереотип отчуждения.

Сочетание пиков на шкалах Ра и Ма ( $6 \uparrow 9)$ отражает большую последовательность и целенаправленность поведения, организованного вокруг определенной концепции или сверхценных идей.

\section{Выво $\triangle ы$}

Таким образом, при анализе данных патопсихологического обследования, проведенного в разных клинических случаях, мы увидели соответствие основным патопсихологическим симптомокомплексам, характерным для разных видов ПОС. Средством организации процесса реабилитации больных, страдающих расстройствами органического спектра может являться программа психологической реабилитации, включающая несколько направлений работы клинического психолога: психологическое образование пациентов и их родственников в части организации повседневного быта и переобучению пациентов утраченным повседневным навыкам; восстановительная тренировка нарушенных когнитивных функций; обучение использованию стратегий компенсации функционального дефицита, тренинг социальных навыков.

\section{ЛИТЕРАТУРА}

1. Зейгарник Б.В. Патопсихология / Б.В. Зейгарник. - М.: Академия, 2007. - 208 с.

2. Рубинштейн С.Я. Экспериментальные методики патопсихологии и опыт применения их в клинике: учебное пособие / С.Я. Рубинштейн. - М.: АпрельПресс, 2010. - 220 c.

3. Блейхер В.М. Клиническая патопсихология: руководство для врачей и клинических психологов / В.М. Блейхер, И.В. Крук, С.Н. Боков. - М.: МПСИ, 2009. $624 c$

4. Соловьева С.Л. Медицинская психология: конспект лекций / С.Л. Соловьева. - М.: АСТ, 2004. - 154 с.

5. Загорная Е.В. Основы патопсихологии / под ред. С. Л. Соловьевой. - М.: Мир науки, 2018. - 209 с. 